\title{
Hartmut Foerstner in cooperation with Ulrich Lanz: Osteosynthesis of the hand: instruments, implants and techniques
}

\section{Thieme Verlag New York, Stuttgart, Delhi, Rio de Janeiro, 2016, 200 pp; 775 III., Hardback, 199.99€, ISBN 978-3-13-203811-0}

\author{
Pierre Kehr ${ }^{1}$. Alain G. Graftiaux ${ }^{1}$
}

Received: 31 October 2017 / Accepted: 17 November 2017 / Published online: 28 November 2017

(c) Springer-Verlag France SAS, part of Springer Nature 2017

This book is based on a 40-year experiment of the surgery of the hand and with for goal to bring clear and richly illustrated information on the methods of internal osteosynthesis to the hand and the wrist, but while leaving of with dimensions the preserving treatment of which it is not the subject here. It is interesting that the authors included there obsolete methods which can still do favors in typical cases as well as information on the techniques being able to involve side effects.

The first four chapters relate to general information on the treatment of the fractures. The fifth chapter treats indications according to the various features of fracture and the various bones of the fingers, metacarpus and carpus. The three following chapters treat operational instruments, implants and postoperative care. The ninth chapter initially describes the various ways according to the types of fractures and the various localizations. The tenth chapter treats various surgical procedures. At the end of the book a rich bibliography is gathered which will usefully make it possible to supplement a book already particularly rich.

That $\mathrm{Ci}$ will interest any surgeon having to treat the traumatology of the hand, sometimes making it possible to consolidate it in its choices, but also to guide it in the sometimes complex cases as one can find some in the accidents.

\section{Compliance with ethical standards}

Conflict of interest The authors declare that they have no competing interests.
Pierre Kehr

pierre.kehr@gmail.com

1 Strasbourg, France 